1578 THE GLOBALLY HARMONISED SYSTEM CHEMICALS IMPLEMENTATION IN ORDER TO STABLISH HEALTH AND ENVIRONMENTAL RISKS (SUCCESSFUL INDUSTRY CASE)

AL Fajardo Montiel, HU Ramirez Sánchez, ARMeulenert Peña. Universidad de Guadalajara, Guadalajara Jalisco México

\subsection{6/oemed-2018-ICOHabstracts.278}

Introduction The GHS (The Globally Harmonised System of Classification and Labelling of Chemicals) is a specially system for standardising and harmonising the classification and labelling of chemicals at the industry. The main objective is to define health, physical and environmental hazards of chemicals. Due there is no international implementation procedure for the GHS, existing systems should develop transition strategies in order to fulfil the

GHS requirements, and be sure to fulfil new ISO 14001:2015 requirements

Methods According with the Mexican standard NMX-R-019SCFI-2011, the classification of chemicals or mixtures incorporates this three steps: Identifying relevant data on the hazards of the substance or mixture, Analysis to identify hazards associated with the substance or mixture and stablish the corresponding hazard communication.

The label system is designed including: Warning words, danger indication, precautionary statements and pictograms, supplier identification and Material safety data sheet information.

After the organisation get this documents, starts the basic elements that include: aquatic toxicity, potential or actual bioaccumulation; degradation (biotic or abiotic) of organic chemicals; and chronic aquatic toxicity. The health hazards is determinate according ONU Purple book (part III).

The final stage include to design a specific procedure al the industry in order to determinate health and environmental risk with a complete methodology to fulfil ISO 14001:2015 standard.

Results One of the main issues is to be sure that the Material safety data sheet provide complete information on a chemical, transportation and emergency actions, with the complete information an according ISO 14001:2015 standard the industry get an specific procedure to integrate GHS requirements with an update process, and then be ready to implement this at Mexico Region,

Conclusion This is the first time that an international standard with a local legislation is integrated and develop a methodology that is effective at different buildings in the same company

\section{EDUCATION ABOUT HEALTH PROTECTION OF HEALTHCARE WORKERS RELATED TO HAZARDOUS DRUGS IN CROATIAN HOSPITALS}

${ }^{1}$ Bojana Knezevic, ${ }^{2}$ Ivana Kerner. 'University Hospital Centre Zagreb, Zagreb, Croatia; ${ }^{2}$ Health Institution for Occupational Health Bonifarm, Zagreb, Croatia

\subsection{6/oemed-2018-ICOHabstracts.279}

Introduction Hazardous drugs have one or more following characteristics: carcinogenicity, teratogenicity, reproductive toxicity, organ toxicity at law doses and genotoxicity. Health care workers who prepare or administer the hazardous drugs (e.g. cancer chemotherapy drugs) or who work in places where these drugs are used may be exposed to these agents in the workplace. In Croatia there are no legal regulatory acts and there are no national guidelines to define how to protect healthcare workers who are at risk of exposure to cytotoxic drugs.

Aim of this case report is to show good practice of health protection of healthcare workers in University Hospital Centre (UHC) Zagreb.

Methods Training course was organised by the UHC for all healthcare workers who might be exposed to cancer chemotherapy drugs. Health assessments of all those workers were provided by occupational health physician who have contracted with the employer and provide the health surveillance of workers who are in the risk for health and safety.

Result There were 5 training courses during the period of two years (2015-2017.) Out of 250 workers, 200 participated in the training course. All workers who were in the risk of exposure to cytotoxic drugs have to visited occupational health institute for health assessment (prior to exposure and at regular intervals thereafter). All workers, who were examined for that workplace, had fitness for work. Workers were no suffering ill-health due to possible exposure.

Conclusion UHC organised the training course to raise awareness about the hazardous drugs in hospital and improve knowledge and safety at work of healthcare workers. The obligation of the employer is to assess the hazards and dangerous at the workplace and manage the risk of exposure to carcinogens or mutagens. This process shall be renewed regularly.

\section{USE OF A RISK ASSESSMENT TO ASSIST FARMERS WITH OSH MANAGEMENT IN IRELAND}

1J McNamara*, ${ }^{2} \mathrm{P}$ Griffin, ${ }^{3} \mathrm{~J}$ Phelan, ${ }^{3} \mathrm{~J}$ Kinsella. ${ }^{1}$ Teagasc- Agriculture and Food Development Authority, Kildalton, Co. Kilkenny, Ireland; 'Health and Safety Authority, Dublin 1, Ireland; ${ }^{3}$ School of Agriculture, University College Dublin, Ireland

\subsection{6/oemed-2018-ICOHabstracts.280}

Introduction In Ireland, persons at work, including selfemployed farmers, are subject to the regulatory framework of the Safety, Health and Welfare at Work Act, 2005. This legislation requires the person in control of a workplace to prepare and implement a written workplace specific OSH management programme, referred to as a 'Safety Statement'. The legislation permits workplaces employing three or less workers to complete a Risk Assessment (RA) prepared under a statutory Code of Practice (COP) as an alternative to completing a Safety Statement. Following enactment of the 2005 legislation, the Irish Health and Safety Authority and Teagasc - the Irish Agriculture and Food Development Authority formed an alliance to: prepare the COP and RA; assist farmers to implement the RA, with or without half-day training, and to evaluate RA utility. This paper outlines some findings of evaluations related to RA completion and control implementation.

Methods RA documents from farmers $(n=335$, with training; $\mathrm{n}=135$, without training) were obtained and controls specified for action assessed. Farm audits $(n=94)$ were undertaken for farms where a RA document was obtained to assess implementation of RA controls specified and farm OSH standards. Data was analysed using SPSS.

Results The evaluation found that farmers specified, on average, 3 controls (2.94\% of controls in RA) for implementation 
following RA completion. Farmers who completed half-day training specified $40 \%$ more controls. Farmers who implemented the controls they specified had a significantly higher percentage of farms with satisfactory OSH standards (92.1\%) compared to those who did not implement controls (56.5\%). Conclusion The study concluded that completion of the RA in association with training led to more specification of controls. It also concluded that while the RA has positive utility among adopter farmers, more comprehensive approaches are needed to support its use among farmers challenged to implement OHS control measures.

\section{DEVELOPMENT OF HUMAN RESOURCES FOR THE PREVENTION OF NEGATIVE EFFECTS OF OVERWORK ON HEALTH IN JAPAN}

Yosuke Miyazaki*, Hisanori Hiro, Kazuaki Kawai, Hiroto Izumi, Yoshiyuki Shibata, Tomonori Igarashi, Kazunori Ikegami, Seichi Horie. University of Occupational and Environmental Health, Japan

\subsection{6/oemed-2018-ICOHabstracts.281}

Introduction Karoshi (death from overwork) has been a difficult challenge in Japanese society for a long time. In July 2015, the cabinet of Japan approved a guideline required by the Act on Promotion of Preventive Measures against Karoshi and other Overwork. In response to the guideline, the University of Occupational and Environmental Health, Japan (UOEH) launched a project to develop human resources to prevent harmful health effects from overwork. This report summarises the programmes for human resources development provided by UOEH

Methods The Centre for Stress-related Disease Control and Prevention (CSDC) was established at UOEH to perform development of human resources in April 2016. At first, the CSDC created a special training programme for 35 experienced occupational physicians who are certificated by the Japan Society for Occupational Health, to improve their understandings of health issues arising from overwork. Those physicians who completed this programme were appointed as on-site lecturers of UOEH. Then, the CSDC delivered various seminars together with the on-site lecturers, targeting occupational physicians, nurses, hygienists and human resource personnel around Japan to let them prevent and overcome the adverse health effects from overwork. Questionnaires were provided to the participants in the seminars for their improvement.

Results All except for one occupational physicians completed the special training programme in 2016. Regarding the seminars, the total number of participants by July 2017 was counted as 355. All together $69 \%$ of the participants responded to the questionnaires and $93.4 \%$ of the responders were satisfied with the seminars. Furthermore, $86.7 \%$ of them thought the skills and knowledge provided through the seminars were applicable to their work.

Conclusion The CSDC, an organisation at UOEH, was established to rise on-site lecturers and to deliver seminars with them for the prevention of the adverse health effects from overwork.

\section{6 \\ PHYSICAL EXERCISE DURING WORKING HOURS FOR EMPLOYEES AT A HOSPITAL LAUNDRY - A QUALITATIVE PROCESS EVALUATION}

${ }^{1} \mathrm{MB}$ Panduro*, ${ }^{2} \mathrm{LL}$ Andersen, ${ }^{1} \mathrm{~L}$ Brandt. ${ }^{1}$ Clinic of Occupational and Environmental Medicine Odense University Hospital, Denmark; ${ }^{2}$ National Research Centre for the Working Environment, Denmark

\subsection{6/oemed-2018-ICOHabstracts.282}

Introduction The present study is to provide an understanding of the motivational factors and barriers that influence compliance with physical exercise during working hours that are aimed at reducing musculoskeletal disorders, for employees at a hospital laundry.

Methods This study used a semideductive, thematic, and structured in-depth interview that was nested in an ongoing project with 140 laundry employees at a hospital laundry with 3 different geographic locations, that have been physical active at work since January 2015. The interviews was conducted 72 weeks within the main project among 22 informants with diverse field of laundry work, where the majority participated in the resistance band training at the workplace for $5 \mathrm{~min}$, three times per week. The following factors, organisational, implementational, and individual motives and barriers were explored.

Result The results indicates that there should be attention to the interaction between management, the employees and the aim of the intervention, since the main barrier for compliance in this study is internal working culture. The results emphasised a certain need of clear connexion between the management's intentions of the implementation of physical exercise at work and the actual implementation. There was also a strong correlation between the employee's motivation and participation in relation to the manager's participation at the daily physical exercise at the workplace. Additionally the results emphasise the importance of ensuring the cooperation among manager's, participants and colleagues in order to ensure compliance regarding the intervention.

Discussion Our recommendations from this study suggest a thorough pre-evaluation in order to analyse the organisational and implementation factors before the implementation of physical exercise at work.

\section{SUFFERING AT WORK AMONG MEDICAL STUDENTS: QUALITATIVE STUDY USING SEMI-STRUCTURED INTERVIEWS}

${ }^{1}$ AS Le Provost, ${ }^{2,3,4} \mathrm{R}$ Pougnet, ${ }^{5,6}$ J Pietri, ${ }^{7} \mathrm{~L}$ De Parscau, ${ }^{2,3} \mathrm{~B}$ Loddé, ${ }^{2,3} \mathrm{JD}$ Dewitte. ${ }^{1}$ Centre de Consultations de Pathologies Professionnelles, CHRU, Brest; ' $2 E A$ 4686, Ethique, Professionnalisme et Santé, Université de Bretagne Occidentale, Brest; ${ }^{3}$ Centre de Consultations de Pathologies Professionnelles, Médecine du Travail du Personnel Hospitalier, CHRU, Brest; ${ }^{4} E D$ 507SHS, Ecole doctorale Sciences Humaines et Sociales, Rennes; ${ }^{5}$ Anesthésie, Clinique du Grand Large, Brest; ${ }^{6} \mathrm{CCTV}$, CHRU, Brest; ${ }^{7}$ Service Pédiatrie et Génétique Médicale, CHRU, Brest

\subsection{6/oemed-2018-ICOHabstracts.283}

Introduction Suffering at work among health professionals is a hot topic. Medical students, doctors of tomorrow, are far from being spared. Prevalence of anxiety and mood disorders range from $20.3 \%$ to $69 \%$ for the former and from $12 \%$ to 